\title{
Tessituras no Ensino de Química: interfaces para abordagem das questões étnico-raciais na sala de aula
}

\author{
Writing in Chemistry Teaching: interfaces for addressing ethnic- \\ racial issues in the classroom \\ Larissa da Fonseca Conceição (lariufrb2@gmail.com) \\ Universidade Federal do Recôncavo da Bahia, Grupo de Pesquisa PझQUI - Pesquisa, Ensino e \\ Extensão em Educação Química \\ Lucas dos Santos Gois (lucas-gois@outlook.com) \\ Universidade Federal do Recôncavo da Bahia, Grupo de Pesquisa PGQUI - Pesquisa, Ensino e \\ Extensão em Educação Química \\ Rafaela dos Santos Lima (limasrafaa@gmail.com) \\ Universidade Federal da Bahia, Grupo de Pesquisa P马QUI - Pesquisa, Ensino e Extensão em \\ Educação Química
}

Resumo: Desde a promulgação da lei $\mathrm{n}^{\circ} 10.639$ de 9 de janeiro de 2003 tem-se a obrigatoriedade da inserção no currículo oficial das Redes de Ensino a temática "História e Cultura Afro-Brasileira". No entanto, a sanção da lei não garante a sua utilização enquanto prática pedagógica. Especialmente no Ensino de Química, tem se percebido diversos entraves para a implementação prática dessa legislação que pode estar relacionada com a omissão dessas discussões na formação docente. Assim, com vistas a introduzir a reflexão sobre as questões étnico-raciais propomos uma oficina pedagógica para um grupo de licenciandos em fase final de formação. Acreditamos, portanto, que a consolidação desta oficina agregou conhecimento teórico para os futuros docentes de química acerca das discussões étnico-raciais, além de proporcionar a possibilidade de atuação em uma educação antirracista.

Palavra-chave: Ensino de Química; Relações Étnico-Raciais; Educação Antirracista.

Abstract: Since the enactment of Law No. 10,639 of January 9, 2003, the theme "AfroBrazilian History and Culture" has been included in the official curriculum of the Education Network. However, the sanction of the law does not guarantee its use as a practice. Especially in the Teaching of Chemistry, several obstacles to the practical implementation of this legislation have been perceived, which may be related to the omission of these discussions in teacher training, so in order to introduce reflection on ethnic-racial issues, we propose a pedagogical workshop for a group of students in the final stage of initial teacher training. We believe, therefore, that the consolidation of this workshop added theoretical knowledge for future chemistry teachers about ethnic-racial discussions, in addition to providing the possibility of acting in an education anti-racist.

Keyword: Chemistry teaching; Ethnic-Racial Relations; Anti-racist education.

\section{O PRELÚDIO... O QUE NOS LEVA A TECER}

Recebido em: $21 / 05 / 2020$

Aceito em: 25/08/2020 
De acordo com os Parâmetros Curriculares Nacionais para o Ensino Médio (PCNEM), o processo de aprendizagem dos conteúdos referentes à Química, está relacionado ao fato dos alunos entenderem as transformações presentes no mundo físico, e dessa maneira, poder julgar de forma crítica as informações provindas do conhecimento popular, da mídia e, além disso, da própria escola. Esse conhecimento deve proporcionar ao aluno o entendimento dos processos químicos presentes em si, e também, proporcionar, a compreensão do saber científico em relação às aplicações e implicações ambientais, sociais, políticas e econômicas (BRASIL, 1999).

Marcondes (2008) afirmou que, mediante a uma reflexão sobre o componente curricular Química ministrado no ensino médio, é possível observar o distanciamento entre as reais necessidades para a formação do discente e os currículos. Logo, consideramos a necessidade do questionamento sobre "[...] o que se deve fazer na escola para que o aluno aprenda Química, perceba as relações entre esta Ciência, a sociedade e a tecnologia e contribua para seu desenvolvimento pessoal, de sua participação consciente nessa sociedade. "(MARCONDES, 2008, p. 68).

Nessa perspectiva, a utilização da contextualização no ensino de Química

[...] é motivada pelo questionamento do que nossos alunos precisam saber de Química para exercer melhor sua cidadania. Os conteúdos a serem tratados em sala de aula devem ter uma significação humana e social, de maneira a interessar e provocar o aluno e permitir uma leitura mais crítica do mundo físico e social (MARCONDES, 2008, p. 69).

Desse modo, pensando no processo formativo dos futuros professores de Química na perspectiva de vivenciar momentos de discussões que aproximem os futuros docentes de uma educação pautada nas compreensões das necessidades educacionais e de discutir temas emergentes no contexto social é que buscamos discutir neste trabalho as potencialidades da realização de uma oficina com a abordagem das relações étnicoraciais e o ensino de Química. Acrescenta-se que discutir as relações étnico-raciais deve fazer parte do processo de formação de professores, tendo em vista que a Lei ${ }^{\circ} 10.639$ de 9 de janeiro de 2003 preconiza a inserção no currículo oficial da Rede de Ensino a obrigatoriedade da temática "História e Cultura Afro-Brasileira". Assim, compreendemos que para que isso se verbalize na escola é fundamental que o professor tenha durante a sua maturação acadêmica a possibilidade de discussão e formação para inserção na sua prática docente do que prescreve a lei. 


\section{QUESTÕES ÉTNICO-RACIAIS}

Antes de dialogarmos sobre as questões étnico-raciais entendemos que seja importante apresentarmos alguns conceitos para guiar a nossa discussão. Assim, abordaremos a seguir os conceitos de preconceito, raça, racismo, etnia e o termo étnicoracial.

\subsection{COMPREENDENDO CONCEITOS}

Iniciaremos aqui uma breve definição do que neste trabalho será compreendido como preconceito. Conforme Gomes (2005), este termo se trata de um julgamento antecipado e negativo feito a integrantes de um determinado grupo religioso, social ou racial. Sendo que, este julgamento antecipado tem como característica a inflexibilidade, pois tende a permanecer, sem considerar fatos que o contrariem. Se tratando do preconceito racial, entendemos que se trata de uma "[...] ideia preconcebida suspeita de intolerância e aversão de uma raça em relação à outra, sem razão objetiva ou refletida." (LOPES, 2005, p. 188).

O conceito de raça, segundo as ideias de Silva e Soares (2011), teve início com a fundamentação biológica, dentro do paradigma das ideias da existência de raça superior e raça inferior, sendo que, esse posicionamento foi reforçado por meio de várias pesquisas realizadas pelos estudiosos da época. Porém, a utilização desse termo para se referir ao segmento negro da população, gerou grandes discussões no campo das Ciências Sociais de um modo geral (GOMES, 2005).

Por tanto, nesse trabalho entendemos que

[...] as raças são, na realidade, construções sociais, políticas e culturais produzidas nas relações sociais e de poder ao longo do processo histórico. Não significam, de forma alguma, um dado da natureza. É no contexto da cultura que nós aprendemos a enxergar as raças. Isso significa que, aprendemos a ver negros e brancos como diferentes na forma como somos educados e socializados a ponto de essas ditas diferenças serem introjetadas em nossa forma de ser e ver o outro, na nossa subjetividade, nas relações sociais mais amplas. (GOMES, p. 49, 2005) 
Logo, de acordo com Munanga (2003), levando em consideração o conceito de raça posto pelas ciências naturais, o racismo é alicerçado na crença da existência de raças superiores a outras. Com isso compreendemos que o racismo é

[...] por um lado, um comportamento, uma ação resultante da aversão, por vezes, do ódio, em relação a pessoas que possuem um pertencimento racial observável por meio de sinais, tais como: cor da pele, tipo de cabelo, etc. Ele é por outro lado um conjunto de ideias e imagens referente aos grupos humanos que acreditam na existência de raças superiores e inferiores. $\mathrm{O}$ racismo também resulta da vontade de se impor uma verdade ou uma crença particular como única e verdadeira (GOMES, 2005, p.52).

É importante ressaltar outro termo que é bastante utilizado no campo das discussões raciais que é o termo etnia. Esse conceito "[...] tem origem do grego ethnos, o que entendemos não só como um conjunto de pessoas da comunidade. É o pertencimento do grupo, independente dos laços consanguíneos e a construção de ações coletivas" (SILVA; SOARES, 2011, p. 106).

Para Gomes (2005), a utilização do termo etnia tem se tornado mais frequente por pesquisadores ao se referir à população negra ou a outros grupos sociais, pelo fato desses entenderem que ao utilizar o termo raça transparece a ideia de que a humanidade é dividida em raças inferiores e superiores, sendo que, esta ideia já foi superada pela ciência. Com isso, alguns estudiosos adotam a expressão "étnico-racial", entendendo que assim haverá uma compreensão melhor da relação de raça e etnia. Sendo que, esta relação é feita com o entendimento de que, ao se referir à população negra brasileira, é essencialmente necessário considerar tanto o valor cultural quanto o valor racial (MUNANGA; GOMES, 2006).

\subsection{CORRENTES (IN)VISÍVEIS: QUESTÕES ÉTNICO-RACIAIS E O ENSINO DE QUÍMICA}

Apesar das discussões voltadas para as questões étnico-raciais, estarem ganhando maior visibilidade, a falta de conhecimento por parte de docentes e gestores, sobre as Diretrizes Curriculares Nacionais para educação nesta perspectiva, associado à falta de interesse em se informar a respeito dos assuntos referentes à diversidade cultural são motivos que evidenciam a dificuldade existente em utilizar essa temática aliada ao ensino de Química (GONZAGA; MARTINS; RAYKIL, 2018). 
É indispensável afirmar que apesar da existência das leis 10.639/03 e 11.645/08, que tratam obrigatoriedade da discussão da "História e Cultura Afro-Brasileira" e da "História e Cultura Afro-Brasileira e Indígena" respectivamente, existem alguns fatores que têm complicado o avanço dessas discussões. Dentre essas razões, Gonzaga, Martins e Raykil (2018) citam a omissão dos gestores na implementação da lei, a formação inicial e continuada de professores insuficiente e a falta de materiais didáticos étnicoraciais nas escolas. Outro fator que é determinante é o entendimento que se tem de currículo e qual o seu papel para a implementação de uma educação antirracista. Concordamos com Neto (2002) ao dizer que o currículo

[...]guarda estreita correspondência com a cultura na qual ele se organizou, de modo que ao analisarmos um determinado currículo, poderemos inferir não só os conteúdos que, explícita ou implicitamente, são vistos como importantes naquela cultura, como, também, de que maneira aquela cultura prioriza alguns conteúdos em detrimento de outros, isto é, podemos inferir quais foram os critérios de escolha que guiaram os professores, administradores, curriculistas etc. que montaram aquele currículo (NETO, 2002, p. 44)

Além disso, Bastos e Benite (2017) dialogam sobre o currículo como instrumentos de poder, que de alguma forma enaltece uma discussão e omite outras. De acordo com os autores,

[...] os currículos são instrumentos de poder e, portanto, hegemônicos e homogeneizantes de tal forma que remontam os modos de poder da ideologia dominante, omitem, não ocasionalmente, o legado dos povos africanos que muito contribuíram para o desenvolvimento do campo da ciência e da tecnologia (BASTOS; BENITE, 2017 p.69).

Nas áreas das Ciências da Natureza e Matemática percebe-se que poucas são as discussões que envolvem temáticas como as relações étnico-raciais. Normalmente, nas disciplinas de Química, Física, Biologia e Matemática há uma preocupação com a aprendizagem do conceito científico de modo isolado, o que ocasiona um distanciamento com a diversidade de saberes existentes nos diferentes contextos. Nesse sentido, percebemos que no ensino de química apesar das diversas possibilidades estas não são exploradas como, por exemplo, o racismo. Sobre a falta de abordagem desta temática na formação inicial do professor de Química Camargo e Benite (2019) afirmam que

O professor de Química lida com uma escola real que é reflexo da sociedade em que está inserida, logo, a formação desse profissional deveria prepará-lo para também compreender o fenômeno do racismo na escola e saber como 
agir quando ele se apresentar em seu ambiente de trabalho (CAMARGO; BENITE, 2019 p. 700).

O racismo está associado à tonalidade de pele que por sua vez corresponde, quimicamente, a pigmentação por meio da melanina. A palavra "melanina" deriva do grego melas, que significa preto; é um polímero proteico, Mota (2006, p.1), sendo um termo que retrata uma variedade de pigmentos de origem natural ou sintéticos. A melanina é um aminoácido, resultado da polimerização da tirosina, sendo ela um componente de muitas proteínas humanas que tem a propriedade de absorver luz. Quimicamente,

[...] os elétrons estão frouxamente localizados em suas ligações conjugadas, duplas e simples, compostas entre elementos de eletronegatividades muito próximas (carbono-nitrogênio-oxigênio). Essa situação permite que a melanina absorva luz de qualquer comprimento de onda, o que atribui a característica cor negra aos corpos. (PINHEIROS, 2008 p.4)
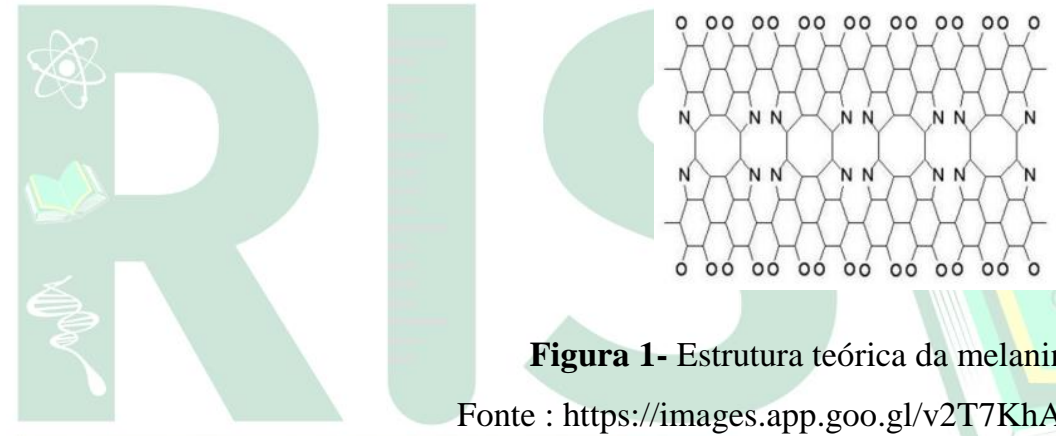

Figura 1- Estrutura teórica da melanina Fonte : https://images.app.goo.gl/v2T7KhAp8QhVXgfv7

Logo, a predisposição genética de cada ser humano também pode contribuir para a quantidade de melanina presente em seu organismo. Outro fator que pode causar o aumento da melanina em um organismo é a exposição à radiação solar. Pinheiros (2008, p.4) diz que, "o bronzeamento causa uma foto-oxidação das moléculas de melanina, estimulando a produção de mais pigmento pelos melanócitos para reduzir a absorção de radiação em excesso".

Existem diversos alimentos que contribuem para que ocorra a produção de melanina no nosso corpo, dentre eles temos: cenoura, abóbora, espinafres, agrião, papaia, tomate, pimentão vermelho e o melão. Todos os alimentos listados são ricos em vitamina A e em betacaroteno (VEIGA, 2007). Podemos perceber a presença da melanina também nos escleródios, que é um fungo causador do mofo-branco esse fungo é capaz de afetar mais de 400 espécies de plantas, esse fungo apresenta um formato esférico, coloração negra e uma casca composta por camadas de células pigmentadas e espessadas. Sua coloração é devido à presença de melanina, que atua como defesa 
contra o dessecamento fazendo com que estes permaneçam viáveis por vários anos, mesmo na ausência de plantas hospedeiras (MEYER, 2014).

Mediante ao que foi exposto, pode-se observar que a melanina não só está presente apenas no organismo humano, mas, também em algumas espécies de plantas, fazendo parte do contexto social e alimentar das pessoas. Assim, a melanina se apresenta como uma temática em potencial como contribuição para o ensino de Química, sendo que por meio dela podemos trabalhar de maneira contextualizada e em uma perspectiva antirracista.

Sobre a contextualização no ensino de Ciências Marcondes e Silva (2010) afirmaram que se trata de um estudo em que são privilegiados a compreensão dos conteúdos por meio dos aspectos que estão envoltos na sociedade, tais como: políticos, sociais, ambientais e entre outros. O ensino pautado na contextualização visa a formação do cidadão crítico e reflexivo que seja capaz de por meio do conteúdo compreender as relações e resolver problemáticas que ocorrem no dia a dia (LIMA, 2020). Já a educação antirracista diz respeito à problematização do racismo no âmbito escolar. De acordo com Francisco Jr (2008) a não problematização do racismo na escola trata-se de uma prática discriminatória.

\section{CONSTRUINDO E ORGANIZANDO A TESSITURA}

Propomos neste estudo uma investigação de abordagem qualitativa. No que diz respeito aos objetivos, compreendemos que se trata de uma pesquisa exploratória que de acordo com Gil (2002, p.41) "tem como objetivo proporcionar maior familiaridade com o problema, com vistas a torná-lo mais explícito ou a construir hipóteses”. Assim, como nesta pesquisa buscamos apresentar possibilidades para o ensino de Química a partir das discussões das questões étnico-raciais, a pesquisa exploratória contempla os nossos objetivos.

Os dados foram obtidos a partir de uma oficina pedagógica realizada com estudantes dos anos finais de formação matriculados em um componente curricular do oitavo semestre do curso de Licenciatura em Química de uma Instituição de Ensino Superior (IES) na Bahia. Participaram da oficina quatro alunos e para assegurar o sigilo 
dos participantes, estabelecemos codificações. Logo, iremos nos referir aos participantes como Lítio, Sódio, Potássio e Rubídio, garantindo assim a integridade dos discentes.

Utilizamos para a execução da oficina a metodologia dos Três Momentos Pedagógicos (3MP) idealizado por Delizóicov (1991). Essa metodologia é organizada da seguinte forma: Problematização Inicial (PI), Organização do Conhecimento (OC) e Aplicação do Conhecimento (AC). A primeira etapa, PI, corresponde ao momento em que são apresentados aos alunos situações problemas, geralmente, presentes em seu contexto. Nesta fase o objetivo é ouvir o conhecimento que os alunos têm, e com isso problematizar. Atuando como mediador, o professor deverá estimular e questionar as respostas destes alunos, observando as possíveis contradições e/ou limitações e direcionando o momento para a superação do senso comum (DELIZÓICOV, 1991).

O segundo momento, OC é a fase em que buscamos compreender as indagações da PI por meio dos conhecimentos científicos. Esta etapa pode apresentar um caráter interdisciplinar possibilitando responder aos questionamentos levantados no momento anterior (DELIZÓICOV, 1991). Por fim, o terceiro momento, AC, é o instante em que a partir dos conhecimentos (re)construídos os estudantes deverão ser capazes de retornar a PI para compreendê-la, além de transcender para outras situações. (DELIZÓICOV, 1991).

\section{OS RESULTADOS DAS TESSITURAS}

Levando em consideração os 3MP de Delizóicov, e compreendendo que em uma oficina pedagógica a existência do diálogo é algo que deve ser constante, para favorecer a troca de ideias e a construção de conhecimentos, iniciamos esta oficina com a PI, fazendo alguns questionamentos aos participantes:

- $\quad$ Para você o que é racismo?

- $\quad$ O que você acha que provoca o racismo?

- Você já sofreu racismo?

A partir dessas indagações, os alunos responderam de forma oral, gerando um momento de discussão enriquecedora, proporcionando a problematização e possibilitando ao professor observar alguns limites e potencialidades. 
Ao iniciar os questionamentos, quando perguntado se eles sabiam o que é racismo, muito dos participantes souberam exemplificar uma situação de racismo. Porém, quando perguntado se eles sabiam definir o racismo, percebemos que a definição apresentada se aproximava com definição de preconceito. Consideramos que esses questionamentos nos possibilitaram perceber alguns posicionamentos dos participantes a respeito do tema escolhido para ser discutido.

É importante destacar que, durante as discussões, os participantes relataram o fato de não saberem como tratar a temática étnico-racial em uma aula, sendo que, como argumentado anteriormente esse "não saber como discutir" é um dos fatores que têm dificultado os debates a respeito das relações étnico-raciais no ensino de Química. Além disso, podemos interpretar essa situação como um reflexo da ausência dessas discussões no currículo vigente na época da licenciatura em química dessa IES.

No segundo momento, foi feita exposição oral sobre o racismo, além de apresentar as diferenças entre o racismo, preconceitos, questões raciais e etnia. Aproveitamos o momento para apresentar aos alunos o vídeo " $\mathrm{Eu}$ sou a menina que nasceu sem cor...” com o contexto poético para reflexão sobre as questões étnico-raciais e outro vídeo 2 "Como o melanócito se transforma em melanina" para retratar sobre a melanina. Apresentamos aos participantes a Figura 1 que retrata a via de síntese da melanina e a Figura 2 que apresenta a sua estrutura química, onde é encontrada na natureza, os tipos de ligações químicas presentes na estrutura da melanina e os princípios ativos encontrados em sua estrutura.

Vídeo ${ }^{1}$ https://www.youtube.com/watch?v=o6zEZP7pudQ

Vídeo ${ }^{2}$ https://www.youtube.com/watch?v=DoCJXmJULrY 
Vol. 3, n. 5. Set./Dez.

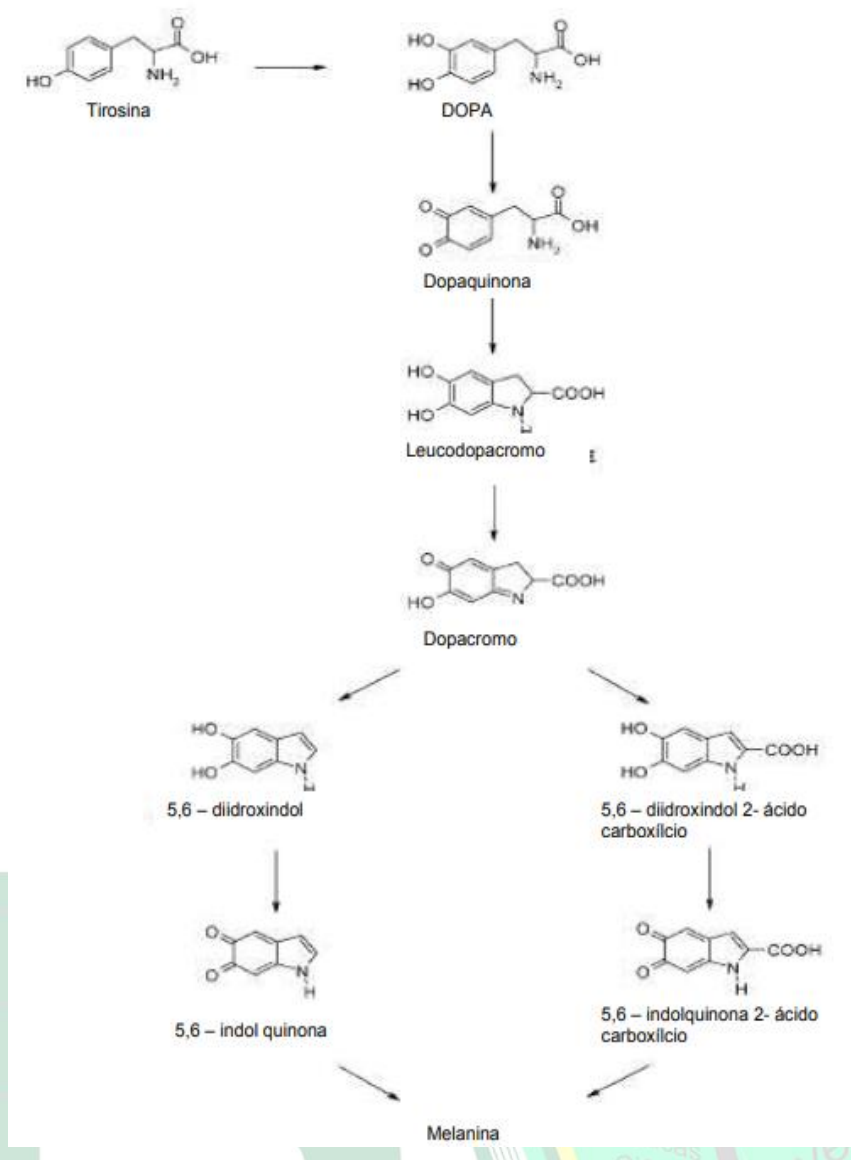

Figura 2- Via de Síntese DA DOPA-Melanina Fonte: Gonçalves (2008)

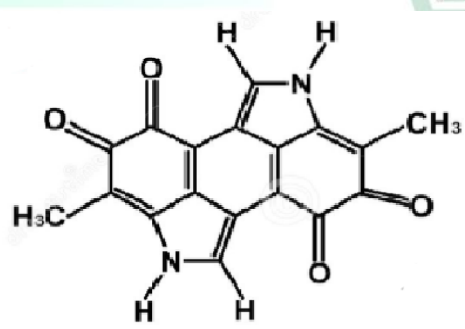

Figura 3- Estrutura Química da melanina

Fonte: https://images.app.goo.gl/Yeukoh1 AJizs8mgy8

Ainda nesse momento foi apresentada aos alunos a história do movimento HIP HOP, como movimento cultural que lutou e luta ativamente em combate ao racismo em diversos aspectos.

Para consolidar a AC, solicitamos que os estudantes construíssem um RAP/Poesia a partir da discussão realizada na oficina. Assim, obtivemos como produto a construção 
de 4 (quatro) raps, que neste caso também pode ser entendido como uma poesia que serão apresentados a seguir.

\section{Poesia produzida pelo Lítio}

Se tratando de questões étnicas raciais

Quase não se ouve nas disciplinas até então

Muito menos da melanina que na pele da pigmentação

Ignorando-se o racismo que se faz presente até então.

Nesta poesia, é possível observar algumas críticas tecidas por Lítio em poucos versos de seu texto. Nos primeiros dois versos o participante fala sobre a ausência das discussões voltadas para as questões étnico-raciais nas disciplinas ministradas no curso de licenciatura em Química. Nos dois últimos versos é perceptível que por falta de discussões voltadas para as questões raciais, o racismo é por vezes ignorado, assim como a melanina que tem como uma de suas propriedades a pigmentação da pele, e poderia ser um tema utilizado para promover a contextualização nas disciplinas ministradas.

\section{Poesia produzida pelo Sódio}

A melanina é uma proteína

Foi o que eu aprendi nessa oficina Que podemos nos conteúdos utilizar

Para em nossa aula contextualizar.

O racismo não é muito discutido

$O$ racismo às vezes é até omitido

A quem pratica sem perceber

A quem faz isso por desmerecer.

No primeiro parágrafo Sódio traz em seus versos, a observação de que a proteína melanina pode ser abordada nos conteúdos de forma contextualizada, evidenciando que esta informação foi adquirida com a participação na oficina em questão. Já no segundo parágrafo, Sódio expõe o fato de que não há discussões sobre o racismo, deixando implícito o fato de que por falta de conhecimento existem pessoas que o praticam. Ainda neste parágrafo, o referido aluno escreve sobre a omissão do racismo, e que, de fato, existe quem o pratica de forma consciente.

\section{Poesia produzida pelo Potássio}

Em uma peça de teatro abordaram um certo tema Acreditando que o preconceito é apenas um dilema

Recebido em: $21 / 05 / 2020$

Aceito em: 25/08/2020 
Ao final de tudo isso viram o problema

Existe outros conceitos para somar o posto tema

No seu primeiro parágrafo Potássio aborda, de forma metafórica a falta de discussão sobre o preconceito, e além disso, a forma como este é apresentado. Com isso, na última compreende-se que esta temática pode ser abordada de forma contextualizada.

\title{
Poesia produzida pelo Rubídio
}

\author{
O tema racismo é tema bom de discutir \\ Questão social é importante \\ Mas não pode esquecer do indagante \\ Para atender todos os integrantes \\ Conhecimento discerne as ideias \\ Pois a discussão faz pensar \\ Para o ponto de vista não parar \\ Nem as opiniões se calar. \\ Discutir racismo é preciso \\ É história com visão \\ Ainda que muitos fechem o coração \\ Pois existem muitos sem noção.
}

Rubídio, em seu texto, deixa explícito que o racismo é um tema importante para ser discutido, e o conhecimento é fundamental para a realização desta discussão. O discente ainda ressalta sobre a importância destas discussões para a conscientização da população, tendo em vista, de que muitos ainda o praticam.

\section{ALGUMAS CONSIDERAÇÕES SOBRE AS TESSITURAS, MAS LONGE DE SEREM FINAIS...}

A escola como âmbito de formação educacional institucional precisa se tornar um espaço não apenas de aprendizagem conteudista, mas assim como recomendação dos próprios documentos que norteiam a educação, a escola precisa ser um espaço plural e esta pluralidade abarca as compreensões sobre a nossa estrutura social que muitas vezes se pauta na negação do racismo, das questões étnico-raciais e da cultura africana. Os espaços acadêmicos de formação docente podem estar colaborando com a ausência 
dessas discussões na Educação Básica, uma vez que na formação inicial percebe-se a omissão dessas reflexões.

Mediante ao exposto é possível observar que os participantes da oficina perceberam a ausência de discussões voltadas para as relações étnico-raciais no decorrer de sua formação. Assim, acreditamos que a realização deste momento tenha sido um espaço fulcral para que os futuros docentes começassem a refletir sobre a necessidade de discussão das questões étnico-raciais no âmbito de formação. Além disso, esperamos que por meio desta oficina os licenciandos possam buscar meios de atuar na perspectiva das relações étnico-raciais e de uma educação antirracista.

Sabemos que apesar dos esforços realizados no combate ao racismo, ainda nos deparamos com diversos casos dessa natureza, seja ele direta ou indiretamente. A escola enquanto espaço de formação para a cidadania não pode se ausentar de discutir tais questões.

\section{AS LEITURAS QUE AJUDARAM A CONSTRUIR AS TESSITURAS}

AFRIKA, L. O Que Faz as Pessoas Pretas Serem Pretas. 2009. Disponível em :< https://estahorareall.wordpress.com/2015/07/28/melanina-o-que-faz-as-pessoas-pretasserem-pretas-negritude-bioquimica-llaila-afrika/ > Acesso em: 02 set 2019.

BARNES C. MELANINA: A Chave Química para a Grandeza Preta. Disponível em:< https://estahorareall.wordpress.com/2015/08/04/melanina-a-chave-quimica-paraa-grandeza-preta-carol-barnes/ > Acesso em: 02 set 2019.

BASTOS, M. A.; BENITE, A. M. C. Cultura africana e ensino de química: estudo sobre a formação docente. Revista da Associação Brasileira de Pesquisadores/as Negros/as (ABPN), v. 9, n. 21, p. 64-80, 2017.

BRASIL. PCNEM: Parâmetros Curriculares Nacionais do Ensino Médio. Brasília: MEC; SEMTEC, 1999.

CAMARGO, M. J. R.; BENITE, A. M. C. Educação para as relações étnico-raciais na formação de professores de química: sobre a lei 10.639/2003 no ensino superior. Quim. Nova, V. 42, n. 6, p. 691-701, 2019. 
DELIZOICOV, D. Conhecimento, tensões e transições. São Paulo, SP: USP, 1991. Orientador: Luis Carlos de Menezes. Originalmente apresentada como Tese de Doutorado, Universidade de São Paulo, Faculdade de Educação,1991.

FRANCISCO JUNIOR, W. E. (2008). Educação anti-racista: reflexões e contribuições possíveis do ensino de ciências e de alguns pensadores. Ciência \& Educação, 14(3), 397-416.

GOMES, N. L. Educação e relações raciais: refletindo sobre algumas estratégias de atuação. In: Kabengele Munanga. (Org.). Superando o racismo na escola. 2 ed. Brasília: MEC, 2005, v., p. 143-154.

GONÇALVES, R. C. R. Estudo da estrutura e da atividade biológica do pigmento melanina produzido pelo fungo Aspergillus nidulans. 2008. $151 \mathrm{f}$. Tese (doutorado) Universidade Estadual Paulista, Instituto de Química., 2008. Disponível em: <http://hdl.handle.net/11449/100739>.

GONZAGA, K. R.; MARTINS, A. R.; RAYKIL, C. O professor de química e a lei 11.645/08: discutindo a educação das relações étnico-raciais em Porto Seguro. Revista Eletrônica Científica Ensino Interdisciplinar, v. 4, n. 10, p. 51-68, 2018.

LIMA, R.S. CONCEPÇÕES DE FUTUROS PROFESSORES DE QUÍMICA SOBRE A CONTEXTUALIZAÇÃO. Dissertação (Mestrado em Educação Científica e Formação de Professores), Universidade Estadual do Sudoeste da Bahia (UESB), Jequié, 2020.

LOPES, V. N. RACISMO, PRECONCEITO E DISCRIMINAC: O Procedimentos didatico-pedagogicos e a conquista de novos comportamentos. In: Kabengele Munanga. (Org.). Superando o racismo na escola. 2 ed. Brasília: MEC, 2005, v., p. 185204.

MARCONDES, M. E. R. Proposições metodológicas para o ensino de Química: oficinas temáticas para a aprendizagem da ciência e o desenvolvimento da cidadania. Em Extensão, v. 7, 2008.

MEYER, M. C.; Hercules D. C.; Claudia V. G. Mofo-branco: desafios do manejo na cultura da soja. Revista cultivar, n.181.p. 22-24, 2014. Disponível em : < https://www.grupocultivar.com.br/artigos/mofo-branco-desafios-do-manejo-na-culturada-soja > acesso em: 18/04/2020.

MOTA, Jociely P.; BARJA, Paulo Roxo - Classificação de Fototipos de Pele: Análise Fotoacústica Vesus Análise Clínica - UNIVAP/IP\&D/fasbio - 2006 http://cronos.univap.br/cd/INIC_2006/epg/03/EPG00000385-ok.pdf acesso em 13/07/2020

MUNANGA, K. Uma abordagem conceitual das noções de raça, racismo, identidade e etnia. In: SEMINÁRIO NACIONAL RELAÇOES RACIAIS E EDUCAÇÃO-PENESB. Rio de Janeiro, 2003. Anais... Rio de Janeiro, 2003. Disponível 
Vol. 3, n. 5. Set./Dez.

\section{ISSN: 2595- 4520}

em: <http://www.acaoeducativa.org.br/downloads/09abordagem.pdf >. Acesso em: 15 dez 2019.

PINHEIRO, A. N. A química dos pigmentos. São Paulo, 2008 Disponível em < http://gpquae.iqm.unicamp.br/textos/T10.pdf> Acesso em 15 Jan 2020.

SILVA, E. L.; MARCONDES, M. E. R. Visões de contextualização de professores de química na elaboração de seus próprios materiais didáticos. Ensaio Pesquisa em Educação em Ciências, v. 12, n. 1, 2010.

SILVA, M. A. L., SOARES, R. L. S. "Reflexões sobre os conceitos de raça e etnia." Entrelaçando-revista eletrônica de cultura e educação. Bahia 2.4 (2011): 99115 .

VEIGA NETO, A. Cultura e Currículo. Contrapontos - ano 2 - n.4 - Itajaí, jan/abr 2002.

VEIGA, S. "Como produzir melanina no corpo"”. Disponível em: <https://beleza.umcomo.com.br/artigo/como-produzir-melanina-no-corpo-2187.html > acesso 16/12/2019.

Recebido em: $21 / 05 / 2020$

Aceito em: 25/08/2020 